\title{
Environmental risk assessment of radon from ceramic tiles
}

\author{
A.F. MAGED ${ }^{1}$, L.Z. ISMAIL ${ }^{2}$, N.L.A. MOUSSA
}

(Manuscript received 1st January 2012, accepted 23 February 2012)

ABSTRACT Radon-222 exhalation from different ceramic tiles depends upon the radium $\left({ }^{226}\right.$ Ra) concentration and porosity. Raw zirconium sand is one of the substances widely used in the ceramic industry and it is naturally radioactive. This can produce unjustified concern and subsequently perturb the market of these products. The radon exhalation rates for all ceramic tile companies were in the ranges $28-44 \mathrm{mBq} \cdot \mathrm{m}^{-2} \cdot \mathrm{h}^{-1}$ and 2.0 to $4.8 \mathrm{mBq} \cdot \mathrm{kg}^{-1} \cdot \mathrm{h}^{-1}$. The porosity of ceramic tiles is in the range $0.19-0.28$. The radium activity of ceramic tiles was found to be in the range $16-38 \mathrm{~Bq} \cdot \mathrm{kg}^{-1}$ for the glazed surface and 23-64 Bq. $\mathrm{kg}^{-1}$ for the clay surface, respectively. The average equivalent dose in contact with the ceramic surface was found to be $22 \mathrm{mSv}^{-1}$. The exposure at working level at the ceramic tile surface was in the range 2.4-3.8 WL. This gives a risk indication to people who spend a long time in closed ceramic tile stores, who should avoid staying for a long time in such places.

Key words: Radon-222 / track density / exhalation rate / ceramic tiles / porosity

\section{Introduction}

Radon is a colorless, odorless, naturally occurring gas, continuously generated from radium-226 by the radioactive decay of uranium-238 together with ionizing radiation. Radon emanates from the earth, and on a smaller scale from certain construction materials (EC, 1999; Tufail et al., 2007; Cortina et al., 2008; Maged, 2009). It is present everywhere and in the open air it rapidly disperses and rarely reaches hazardous concentrations. Most radon inhaled with indoor air is exhaled and remains in the lungs for only a short time. The first radon daughter Po-218 is a very reactive heavy metal and electrostatically attracted to tiny particulates in air. These particulates are inhaled and deposited (as solid-state materials) in the lungs. The radon daughter then decays sequentially, releasing damaging alpha and beta particles. Therefore, it is radon progeny, not radon, that actually causes damage to the bronchial epithelium, because only the progeny remains in the lungs long enough to decay significantly (Cothern, 1987). Ceramics can be particularly radioactive if some compound of uranium (e.g., uranium oxide, sodium urinate)

\footnotetext{
1 National Centre for Radiation Research and Technology (NCRRT), Egyptian Atomic Energy Authority (EAEA), B.O. Box 29, Nasr city, Cairo, Egypt.

2 Physics Department, Faculty of Science, Cairo University, Giza, Egypt.
} 
has been used to impart color (e.g., orange-red, green, yellow, black) to the glaze. The glaze can serve two functions: it provides color, and it seals the ceramic. It is true that the clay used to produce the body of the ceramic (rather than the glaze) can be a source of radon, but this is true for all ceramics, with or without a uranium glaze. Raw zirconium sand is one of the substances (naturally occurring radioactive material, NORM) which is widely used in the ceramic industry (Verita et al., 2009; ICRP, 2007; Luisa et al., 2008). This sand contains varying concentrations of natural radionuclides: mostly uranium-238. Particular attention from a radiological point of view is given to ceramic tiles, which were eventually considered responsible for undue radioactivity (EC, 1996). Consequently, this study was undertaken with the purpose of determining the radon concentration in contact with ceramic tiles, and to assess the annual effective dose rate at the ceramic surface. The radon exhalation rate for different ceramic tile companies used in the Egyptian market and assessment of radium activity were measured.

\section{Materials and methods}

A total of 50 samples of 13 different ceramic tile manufacturers were collected from the Egyptian market for the measurement of the radon exhalation rate. The ceramic tiles (floor and wall tiles) were obtained from suppliers or buildings under construction. The period of the survey was about 15 days for ceramic tiles. The radon exhalation rate of ceramic tiles for both clay and glazed surfaces was measured by CR-39 track detectors.

The radon concentration per unit volume was calculated using the relation given (Maged et al., 1993),

$$
\mathrm{C}=\mathrm{K}^{-1} \rho
$$

where $\rho$ is the number of tracks per $\mathrm{cm}^{2}, \mathrm{~K}$ is the calibration factor, 1.37 track. $\mathrm{cm}^{-2}$. $\mathrm{kBq} \cdot \mathrm{h}^{-1} \cdot \mathrm{m}^{-3}$ inside the hollow holder. The setup to measure the radon exhalation rate ofceramic tiles using CR-39 track detectors and the hollow holder is shown in Figure 1. The CR-39 plastic detectors were removed from the hollow holder and etched chemically in a $6 \mathrm{M} \mathrm{NaOH}$ solution at $70{ }^{\circ} \mathrm{C}$ for $18 \mathrm{~h}$ to display and enlarge the latent alpha tracks due to radon decay. The etched tracks on the detectors were counted, using an optical microscope with objective lens $4 \times$ magnification which was attached to an image analyzer. The average area of one hundred fields of view was calculated by using an image analysis system and the track density was calculated in terms of tracks per $\mathrm{cm}^{-2}$. The background track density was determined by processing a virgin detector under the same etching conditions. The background was subtracted from the measured track density. In order to obtain realistic statistics of the tracks, 100 fields of view were scanned continually to cover the detector surface. 


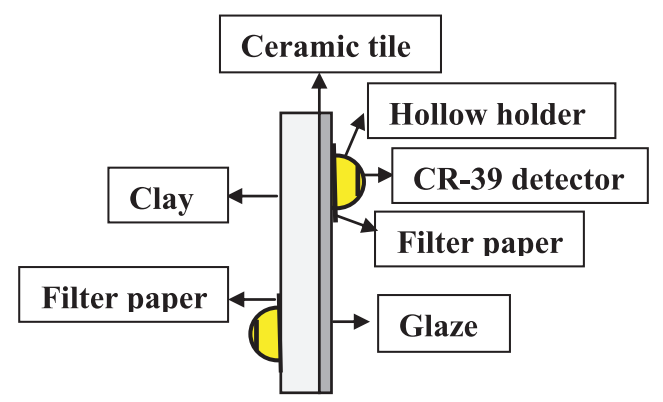

Figure 1 - Setup diagram for measuring the radon exhalation rate of ceramic tiles.

\section{Results and discussion}

\subsection{Radon exhalation rate}

Expressions for the concentration of radon from building materials were derived from several authors (Krisiuk, 1980; Quindos et al., 1987). The radon concentration inside the hollow holder in equilibrium is:

$$
\mathrm{C}=\frac{\mathrm{ES}}{\mathrm{V}\left(\lambda+\lambda_{\mathrm{v}}\right)}+\frac{\mathrm{C}_{0} \lambda_{\mathrm{v}}}{\lambda+\lambda_{\mathrm{v}}}
$$

where $\mathrm{E}$ is the exhalation rate, $\mathrm{S}$ is the surface area of the hollow holder, $\mathrm{V}$ is the volume of the hollow holder, $\lambda$ is the radon decay constant $\left(7.6 \times 10^{-3} \mathrm{~h}^{-1}\right)$, Co is the outdoor radon concentration and $\lambda_{\mathrm{v}}$ is the ventilation rate. For calculating the exhalation rate of ceramic tiles, when it is considered that $\lambda_{\mathrm{v}} \cong 0$, the second term in equation (2) equals zero. The amount of radon transferred from the ceramic into a structure is affected by many factors, including radium content, porosity, construction type and meteorological conditions. The radon exhalation rates for different ceramic tile manufacturers ranged from 2.0 to $4.8 \mathrm{mBq} \cdot \mathrm{kg}^{-1} \cdot \mathrm{h}^{-1}$. A comparison study for the geometric mean for both the mass exhalation rate $\left(3.4 \mathrm{mBq} \cdot \mathrm{kg}^{-1} \cdot \mathrm{h}^{-1}\right)$ and the area exhalation rate $\left(38 \mathrm{mBq} \cdot \mathrm{m}^{-2} \cdot \mathrm{h}^{-1}\right)$ for the average of all ceramic tiles with other authors (Rashmi et al., 2009) showed them to be less than soil samples ( $38 \mathrm{mBq} \cdot \mathrm{kg}^{-1} \cdot \mathrm{h}^{-1}$ and $185 \mathrm{mBq} \cdot \mathrm{m}^{-2} \cdot \mathrm{h}^{-1}$, respectively).

\subsection{Assessment of effective radium concentration}

The radon emanation power or emanation coefficient, denoted by $\varepsilon$, is defined as the fraction of radon-222 produced by the disintegration of radium-226 in the grains of the material that can escape from it. The emanation power is dimensionless and ranges from 0 (no radon escapes from the material) to 1 (all radon escapes). The rate of radon exhalation is proportional to the gradient of the 
TABLE I

Average values and ranges for activity concentrations of naturally occurring radium-226 (EC, 1999).

\begin{tabular}{|c|c|}
\hline Building material & ${ }^{226} \mathrm{Ra}\left(\mathrm{Bq} \cdot \mathrm{kg}^{-1}\right)$ \\
\hline Ceramic & $25-193$ \\
\hline Granite & $\mathrm{ND}^{\mathrm{a})}-160$ \\
\hline Tiles & $33-61$ \\
\hline Marble & $1-63$ \\
\hline Ceramic $^{\text {b) }}$ & $16-64$ \\
\hline
\end{tabular}

a) ND = No data. b) Present work

radon concentration in the internal pores (Culot et al., 1976). The principal factors affecting the radon exhalation rate from building material per unit activity concentration of radium-226 are the porosity and the density of the material, the diffusion coefficient, the water, the age, and the composition of the material, as seen in equation (3)

$$
E=\varepsilon \times \mathrm{C}_{\mathrm{Ra}} \times \rho \times \sqrt{\frac{\lambda \mathrm{D}}{\mathrm{P}}} \times \tanh \left[\frac{\lambda P}{D} \times l\right]
$$

where $\varepsilon$ is the emanation power, $\mathrm{C}_{\mathrm{Ra}}$ is the effective radium concentration, $\rho$ is the density, $\mathrm{D}$ is the effective diffusion coefficient, $\lambda$ is the decay constant of radon$222, \mathrm{P}$ is the porosity of the material, and $l$ is the half thickness of the material.

The activity concentrations of NORM in ceramic tiles vary according to the type and origin of the ceramic tiles. The activity concentration (Bq. $\left.\mathrm{kg}^{-1}\right)$ in the most common building materials in Europe, e.g. concrete and sand-lime bricks, is 40 and 10 for radium-226, respectively (EC, 1999). The radium-226 activity values of NORM for the present study and other authors are shown in Table I. The radium226 activity for all ceramic tiles, either floor or wall tiles, was in the range 16$64 \mathrm{~Bq} \cdot \mathrm{kg}^{-1}$, as shown in Table II. It is clear that the average of radium-226 activity in ceramic tiles in Egypt was less than in the work of other authors (Verita et al., 2009; EC, 1999), as shown in Table III. The average radium concentration (79 Bq. $\mathrm{kg}^{-1}$ ) in clays which are used in the ceramic industry in Serbia (Todorovic et al., 1999) was found to be higher than in the present work $\left(41 \pm 12 \mathrm{~Bq} \cdot \mathrm{kg}^{-1}\right)$. The dependence of the radon-222 exhalation rate on the porosity of ceramic tiles shows no significant difference. The use of industrial by-products and residues containing elevated concentrations of radioactive material in building materials is increasing due to economic and environmental reasons. The national regulatory authorities should ensure that "annual doses are restricted to a few $\mathrm{mSv}$ for the worst-case scenarios" (ICRP, 2007). The dependence of the radon-222 exhalation rate on the radium concentration of ceramic tiles (either floor or wall tiles) for all manufacturers (glazed and clay) show a small increase, as in Figures 2-5. 
TABLE II

Average radium-226 concentration (Bq. $\mathrm{kg}^{-1}$ ) from all ceramic tiles of different manufacturers.

\begin{tabular}{|c|c|c|c|c|}
\hline \multirow{3}{*}{$\begin{array}{c}\text { Code } \\
\text { No. }\end{array}$} & \multirow{2}{*}{\multicolumn{2}{|c|}{$\begin{array}{c}\text { Average radium concentration }\left(\mathrm{Bq} \cdot \mathrm{kg}^{-1}\right) \\
\text { Floor tile }\end{array}$}} & \multirow{2}{*}{\multicolumn{2}{|c|}{$\begin{array}{l}\text { Average radium concentration }\left(\mathrm{Bq} \cdot \mathrm{kg}^{-1}\right) \\
\text { Wall tile }\end{array}$}} \\
\hline & & & & \\
\hline & Glaze & Clay & Glaze & Clay \\
\hline 1 & 33 & 54 & 17 & 24 \\
\hline 2 & 36 & 52 & 23 & 31 \\
\hline 3 & 30 & 59 & 22 & 34 \\
\hline 4 & 24 & 48 & 21 & 32 \\
\hline 5 & 23 & 50 & 16 & 33 \\
\hline 6 & 34 & 56 & 27 & 37 \\
\hline 7 & 31 & 64 & 21 & 34 \\
\hline 8 & 30 & 54 & 26 & 39 \\
\hline 9 & 38 & 56 & 24 & 34 \\
\hline 10 & 26 & 48 & 16 & 29 \\
\hline 11 & -- & -- & 22 & 30 \\
\hline 12 & -- & -- & 17 & 23 \\
\hline 13 & -- & -- & 18 & 27 \\
\hline Mean & 31 & 54 & 21 & 31 \\
\hline $\operatorname{Max}$ & 38 & 64 & 27 & 39 \\
\hline Min & 23 & 48 & 16 & 23 \\
\hline S.D & 5 & 5 & 4 & 5 \\
\hline
\end{tabular}

TABLE III

Activity concentrations of radium-226 in zircon materials and ceramic tiles (Verita et al., 2009).

\begin{tabular}{ccc}
\hline Material & Samples & Average ${ }^{226}$ Ra radioactivity $\left(\mathrm{Bq} \cdot \mathrm{kg}^{-1}\right)$ \\
\hline Zircon materials & 27 & $2640 \pm 650$ \\
Ceramic tiles & 12 & $90 \pm 60$ \\
Ceramic tiles $^{\mathrm{a})}$ & 50 & $33 \pm 13$ \\
\hline
\end{tabular}

a) Present work 
TABLE IV

The average parameter value of ceramic tiles inside a hollow holder for all companies.

\begin{tabular}{|c|c|c|c|c|c|c|}
\hline Code & $\begin{array}{l}\text { Track density } \\
\text { No.cm }\end{array}$ & $\begin{array}{c}\text { Radon concentration } \\
\text { Bq. } \mathrm{m}^{-3}\end{array}$ & $\begin{array}{l}\text { Exhalation rate } \\
\mathrm{mBq} \cdot \mathrm{m}^{-2} \cdot \mathrm{h}^{-1}\end{array}$ & $\begin{array}{c}\text { Equivalent dose } \\
m S v \cdot y^{-1}\end{array}$ & $\begin{array}{l}\text { E.E.C. } \\
\text { Bq. }{ }^{-3}\end{array}$ & $\begin{array}{l}\text { Exposure } \\
\text { W.L }\end{array}$ \\
\hline 1 & 377 & 637 & 37 & 21 & 319 & 3.2 \\
\hline 2 & 431 & 728 & 43 & 24 & 364 & 3.6 \\
\hline 3 & 430 & 727 & 43 & 24 & 363 & 3.6 \\
\hline 4 & 387 & 654 & 37 & 21 & 327 & 3.3 \\
\hline 5 & 381 & 644 & 43 & 21 & 321 & 3.2 \\
\hline 6 & 430 & 728 & 42 & 24 & 364 & 3.6 \\
\hline 7 & 416 & 703 & 41 & 23 & 351 & 3.5 \\
\hline 8 & 434 & 733 & 43 & 24 & 367 & 3.7 \\
\hline 9 & 444 & 751 & 64 & 25 & 375 & 3.8 \\
\hline 10 & 394 & 673 & 38 & 22 & 337 & 3.4 \\
\hline 11 & 331 & 559 & 33 & 18 & 279 & 2.8 \\
\hline 12 & 288 & 486 & 22 & 16 & 243 & 2.4 \\
\hline 13 & 337 & 569 & 33 & 18 & 285 & 2.8 \\
\hline Mean & 390 & 661 & 41 & 22 & 331 & 3.3 \\
\hline Max & 444 & 751 & 64 & 25 & 375 & 3.8 \\
\hline Min & 288 & 486 & 22 & 16 & 243 & 2.4 \\
\hline SD & 46 & 68 & 5 & 2 & 55 & 0.2 \\
\hline P.E. $E^{\text {b) }}$ & (\%) & 12 & 10 & 12 & 9 & 17 \\
\hline
\end{tabular}

a) E.E.C= Equilibrium Equivalent concentration. b) P.E (\%) = Precision error (\%).

\subsection{Effective dose equivalent due to radon-222}

The effective dose equivalent due to radon-222 and its progenies was estimated using the following equation (UNSCEAR, 2000),

$$
\mathrm{H}\left(\mathrm{mSv} \cdot \mathrm{y}^{-1}\right)=\left((0.17+9 \mathrm{~F}) \mathrm{C}_{\mathrm{Rn}}\right) \times 8760(\mathrm{~h}) \times 0.8 \times 10^{-6}
$$

where $\mathrm{F}$ is the equilibrium factor between radon and its progeny, $\mathrm{C}_{\mathrm{Rn}}$ is the concentration of radon-222 and 0.8 is the indoor occupancy factor.

The equivalent dose due to radon concentration inside the hollow holder which is in contact with the ceramic tile's surface is found to be $22 \pm 2 \mathrm{mSv}^{-1}{ }^{-1}$. It is twice as high as the recommended action level $\left(10 \mathrm{mSv}_{\mathrm{y}} \mathrm{y}^{-1}\right)$. The track density, radon concentration, equilibrium equivalent concentration and exposure were in the ranges 288-444 No.cm ${ }^{-2}$, 486-751 Bq.m ${ }^{-3}, 243-375$ Bq.m ${ }^{-3}$ and 2.4-3.8 W.L, respectively, as in Table III. 


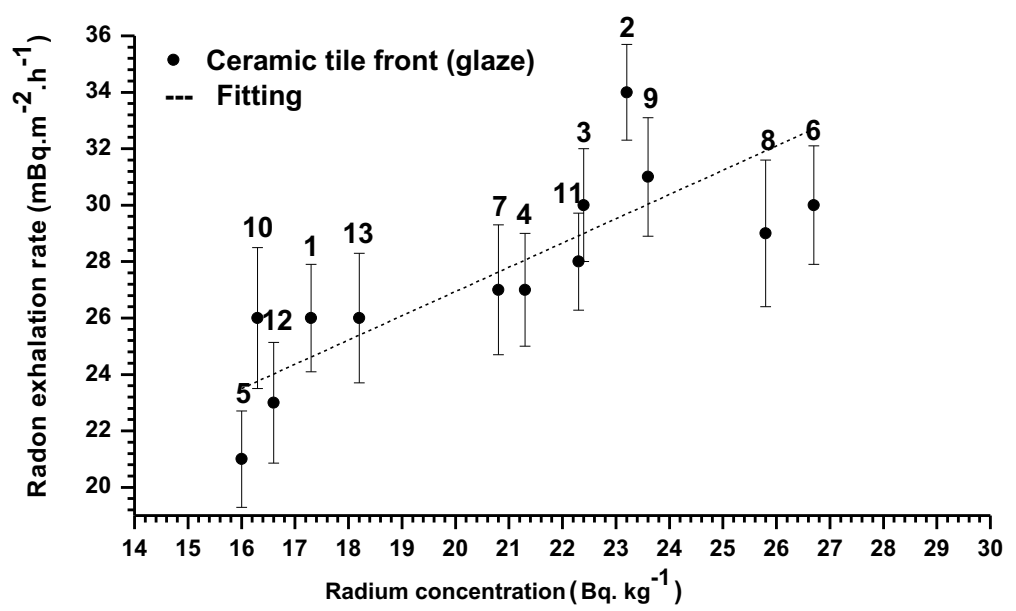

Figure 2-The dependence of the radon exhalation rate from the glazed side on the radium-226 concentrations of wall tiles. Numbers with each point indicate the source manufacturers.

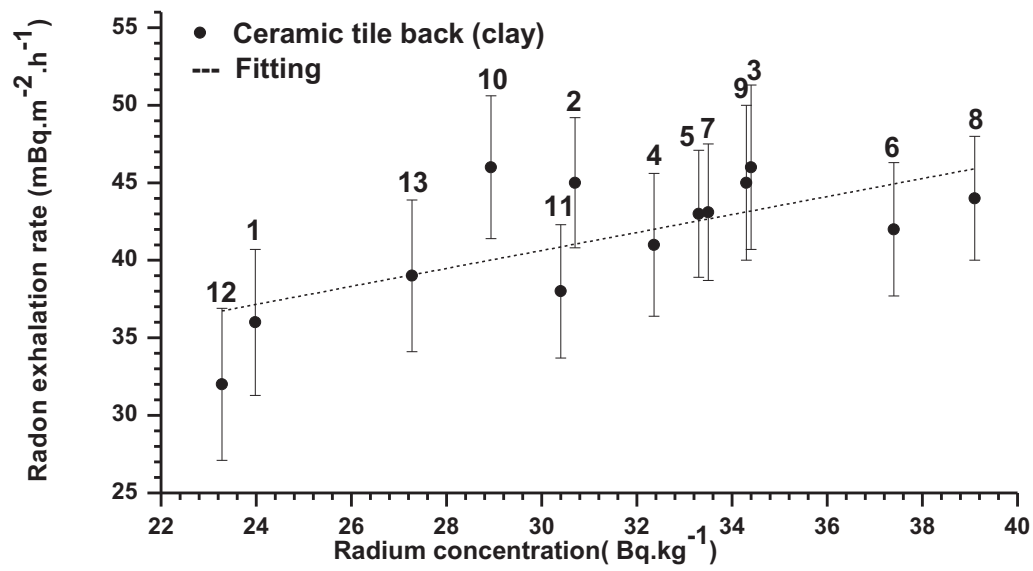

Figure 3 - The dependence of the radon exhalation rate from the clay side on the radium concentrations of wall tiles. Numbers with each point indicate the source manufacturers.

The exposure at working level in contact with ceramic tiles was found to be in the range $2.4-\mathrm{WL}$.

\section{Conclusion}

The recycling of industrial waste or by-products is extensively used in the construction industry. The use of fly ash, coal slag, phosphogypsum and red mud in ceramics 


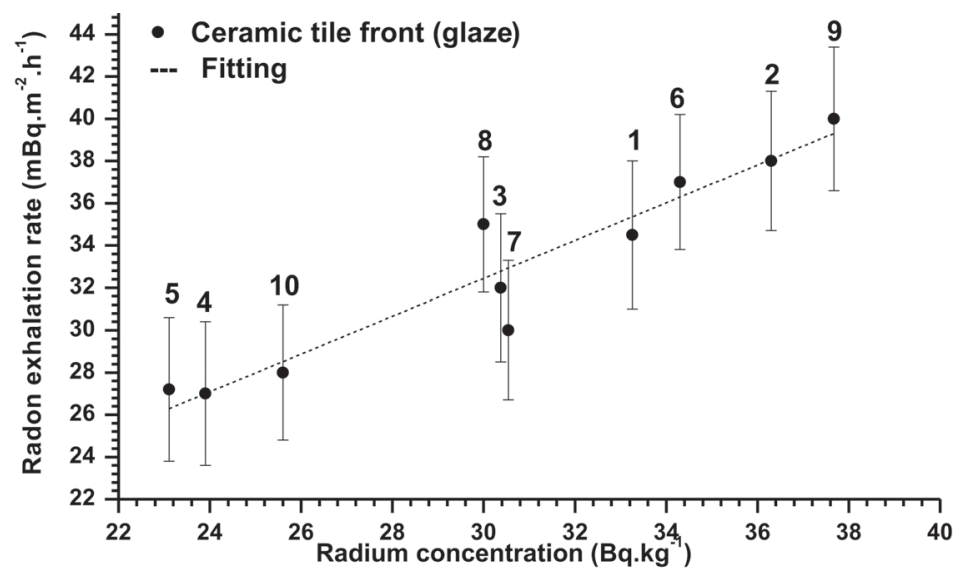

Figure 4-The dependence of the radon exhalation rate from the glazed side on the radium concentrations of floor tiles. Numbers with each point indicate the source manufacturers.

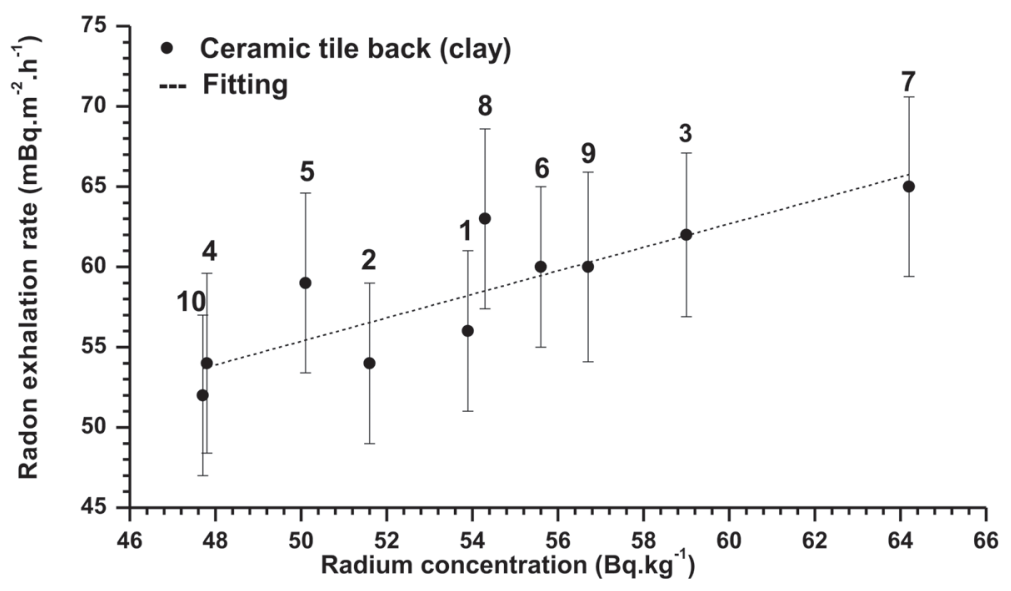

Figure 5 - The dependence of the radon exhalation rate from the clay side on the radium concentrations of floor tiles. Numbers with each point indicate the source manufacturers.

and the increment in radiation exposure from these materials has been of concern for several years. The radon exhalation rates for all ceramic tile companies in contact with the ceramic surface were in the ranges $28-44 \mathrm{mBq} \cdot \mathrm{m}^{-2} \cdot \mathrm{h}^{-1}$ and 2.0 to $4.8 \mathrm{mBq} \cdot \mathrm{kg}^{-1} \cdot \mathrm{h}^{-1}$.

The mean values of radium concentrations of ceramic tiles were in the ranges 16-38 Bq. kg ${ }^{-1}$ for the glazed surface and 23-64 Bq. $\mathrm{kg}^{-1}$ for the clay surface, 
respectively. The equivalent dose in contact with the ceramic tile surface is $22 \pm 2 \mathrm{mSv} \cdot \mathrm{y}^{-1}$. The equivalent dose due to the radon concentration in contact with the ceramic tile surface is twice as high as the recommended action level $\left(10 \mathrm{mSv} \cdot \mathrm{y}^{-1}\right)$. These data must be regarded as preliminary and further more extensive studies should be done on a large scale for all building materials.

\section{REFERENCES}

Cortina D., Duran I., Llerena J.J. (2008) Measurements of indoor radon concentrations in the Santiago de Compostela area, J. Environ. Radioact. 99, 1583-1588.

Cothern C.R. (1987) Estimating the health risks of radon in drinking water, J. Am. Water Works Assoc., April, 153.

Culot M.V.J., Olson H.G., Schiager K.J. (1976) Effective diffusion coefficient if radon in concrete, Theory and Methods for Field Measurements, Health Phys. 30, 263-270.

EC (1999) European Community, Laying down basic safety standards for the protection of the health of workers and the general public against the dangers arising from ionizing radiation, Council Directive 96/29/EURATOM, 1-114.

EC (1999) European Commission, Radiological Protection Principles Concerning the Natural Radioactivity of Building Materials, Radiation Protection Report RP-112, Directorate-General Environment Nuclear Safety and Civil Protection, Luxembourg.

ICRP Publication 104 (2007) International Commission on Radiological Protection, Scope of Radiological Protection Control Measures, Ann. ICRP 37.

Krisiuk E.M. (1980) Airborne Radioactivity in Buildings, Health Phys. 38 (2), 199-202.

Luisa B., Isidoro Z, Josefina O, Vicente S. (2008) Occupational exposure to natural radioactivity in a zircon sand milling plant, J. Environm. Radioact. 99, 1525-1529.

Maged A.F. (2006) Radon Concentration in Elementary Schools in Kuwait, Health Phys. 90 (3), 258262.

Maged A.F. (2009) Estimating the radon concentration in water and indoor air, Environ. Monit. Assess. 152, 195-201.

Maged A.F., Tsuruta T., Durrani S.A. (1993) Experimental and Theoretical Considerations on the Calibration Factor K between -Activity Concentration and Track Density for Application in Radon Dosimetry, J. Radioanal. Nucl. Chem. 170 (2), 423-431.

Quindos L.S, Newton, G.J., Wilkening, M.H. (1987) On the dose rate indoors from building materials, Radiat. Prot. Dosim. 19, 125-128.

Rashmi K., G.S.S. Sharma (2009) Activity measurements and dependence of radon exhalation rate on physical sample parameters in soil samples, Asian J. Chem. 21 (10), 271-274.

Todorovic D., Popovic D., Djuric G. (1999) Radionuclides in raw building materials, Izgradnja 53, 330-335.

Tufail M., Akhtar N., Javied S., Hamid T. (2007) Natural radioactivity hazards of building bricks fabricated from saline soil of two districts of Pakistan, J. Radiol. Prot. 27, 481-492.

UNSCEAR (2000) United Nations Scientific Committee on the Effects of Atomic Radiation, Sources, Effects and Risks of Ionizing Radiation, Report to the General Assembly with Annex B: Exposures from Natural Sources of Radiation, United Nations, New York.

Verita S., Righi S., Guerra R., Jeyapandian M. (2009) Radon exhalation rates from zircon sands and ceramic tiles in Italy, Radioprotection 44, 445-451. 